Abstract for oral presentation at European Scientific Association on Residential and Family Care for Children and Adolescents Conference (EUSARF) conference: Shaping the future. 2016-09-13 - 201609-16, Oviedo, Spain.

\title{
Young People in Limbo: Perceptions of Self-Presentations when Being Assessed in Secure Accommodation
}

Sofia Enell, PhD in Social Work, School of Health and Welfare, Jönköping University

In Sweden, young people are assessed in secure accommodations at the request of the social services. Although this kind of practice has a historical heritage in Sweden, research about their effectiveness and implications is lacking, especially from the assessed young people's perspective. In this oral communication a study about how 16 Swedish adolescents perceived being assessed in a secure accommodation at time of the assessment and in retrospect is presented.

Being assessed can be regarded as being in limbo, a state of uncertainty. The assessed know a change, more or less extensive, is going to come but they do not know what kind of change it is going to be. Young people assessed in residential care, are in the hands of professionals; professionals that might have a profound impact on their lives, as decisions they make might influence the young people's future. Further, being in the limbo of assessment processes could challenges people's perceptions of themselves. Erving Goffman identified institutional processes in total institutions restricting the residents' autonomy to act. Later research has demonstrated that Goffman's concept is still relevant for life in institutions and the processes have been thoroughly described in modern institutions for children and young people. Given the features of assessment processes and of institutions, they both affect what Goffman named as presentations of self (self-presentations). By using Goffman's concepts of self-presentation and institutional processes in total institutions, the aim of the study was to analyse young people's perceptions of being assessed in secure accommodation.

The empirical material consists of three interviews each with 16 young people conducted over a twoyear period. All interviews were semi-structured and an empirical and theoretical analysis was carried out with a focus on the young people's perceptions of their experiences of being assessed in an institution.

Three situations were identified in which the young people felt that their self-presentations were in some way in or out of their control: the placement situation; the assessment situation; and the assessment-outcome situation. The youths perceived their self-presentations to be influenced by the setting (i.e., the institution). Moreover, three audiences for the young people's self-presentations were identifier: the present staff, the not present caseworkers at the social services and the peer group. This entire situation differs significantly from everyday life for youths. It also made the young people's assessment limbo dual, they were involved in one assessment process in the institution and one in the social services realm. It made the time to be of overall and multidimensional uncertainty and consequently lack of control. The young persons' perceptions of themselves were challenged by their perceived contradictory self-presentations that they felt were problematised. To manage, they distanced themselves from their self-presentations or searched for continuity in their self- 
presentations. The analysis of the youth's perceptions raises questions about how vulnerable young people benefit from being assessed in institutions. 